\title{
Late-life suicide in an aging world
}

\author{
Diego De Leo $\mathbb{1}^{1,2}$ 凶
}

\begin{abstract}
Suicide is an important problem among older adults and in particular older men. Risk factors for suicide in older adults include the loss of a loved one, loneliness and physical illness. Suicide in older adults is often attributed to the development of depression due to bereavement or loss of physical health and independence. However, suicide prevention in old age requires avoiding overly simplistic therapeutic approaches. This Perspective discusses the impact of social determinants of health, cultural narratives and the coronavirus disease 2019 (COVID-19) pandemic on suicide among older adults and proposes strategies for a multifaceted approach to suicide prevention.
\end{abstract}

O lder people die by suicide at a disturbing rate. This sad phenomenon occurs more often in older men, particularly those over 80 years of age ${ }^{1}$, especially when facing conditions such as chronic pain and dependence on others, but also when suffering from loneliness, feelings of abandonment and loss of meaning for life $^{2}$. All these conditions are risk factors for suicide ${ }^{3}$; some of these factors can be controlled and their impact limited; some others may simply be too much of a burden on individuals and their families. Ageist attitudes associate old age with physical and cognitive decline (considering older adults to be frail and helpless individuals) and inevitably influence the level of care that these individuals receive $e^{4}$. Thus, opposing ageism (see definitions for key terms in Box 1) can significantly reduce the impact of the risk factors that contribute to suicidal behavior and reduce the number of fatal suicide attempts. Measures to prevent suicide attempts might also reduce suicide risk for others, as there is evidence that exposure to suicide within ones' social group increases the risk of suicidal behavior ${ }^{5}$.

This article provides an overview of existing knowledge on suicide in old age and discusses it in the context of the global aging population, the increase in longevity around the world and the potential impact of the pandemic (Boxes 1,2).

\section{Global aging, longevity and suicide}

Suicide rates have declined globally, and quality of life and access to health care have improved. However, suicide rates of older people remain the highest worldwide ${ }^{1}$ (Fig. 1). In general, there is a progressive increase in suicide rates with age, especially among $\mathrm{men}^{6,7}$, and this trend may continue even among ultra-centenarians $^{8}$. Globally, in 2017, suicide in old age affected 16.17 individuals per 100,000 inhabitants at the age of 50-69 years and 27.45 individuals per 100,000 inhabitants at the age of 70 or more years ${ }^{1}$. With epidemiological data predicting an almost doubling of the older population in less than 30 years $^{9}$ and the increasing proportion of mononuclear families, the concern of increased social isolation, loneliness and addiction, known risk factors for suicide ${ }^{10}$, does not appear unfounded.

Old age is a social concept rather than a true biological one ${ }^{11}$. In fact, there is no clearly defined and universally valid threshold that marks old age, as a person's chronological age is not well linked to their physical and mental capabilities. While chronological age increases at the same rate for everyone everywhere, biological age depends on epigenetic alteration and DNA methylation and related bodily changes occurring in a given person ${ }^{12}$. The threshold for entering old age is generally considered to be 65 years. However, especially in high-income countries, people aged 65-74 years generally enjoy good health and continue to benefit from satisfactory levels of social inclusion and availability of resources as in younger age. In low- and middle-income countries, rather than chronological age, old age seems to be defined by cessation of active participation in society ${ }^{13}$.

Literature relating to suicide in old age also generally considers 65 years as the threshold level; however, given the relative numerical rarity of the phenomenon, many investigations have also included younger individuals ${ }^{14}$. However, especially for a Western country, considering individuals in their fifties or sixties as representative of 'late-life' suicides could lead to misleading interpretations. For example, the lifetime prevalence of major depression, an important risk factor for suicide at any age, decreases significantly after the age of 65 years ${ }^{15,16}$. Therefore, its role may be less relevant in older people than in younger people ${ }^{17}$. It is true that older people may attribute their depressed mood to physical illness or be ashamed to admit the presence of a mental disorder ${ }^{15}$. Even early mortality could explain this relatively low prevalence in a population that is certainly more vulnerable than the younger on $\mathrm{e}^{18}$. Conversely, the presence of somatic diseases in suicide increases proportionally with aging, becoming very frequent after the age of 85 years $^{19}$.

The underestimation of death rates from suicide is an important phenomenon everywhere, far from being trivial ${ }^{20}$. Suicide death rates of older adults are particularly liable to be underestimated ${ }^{21}$. In a number of cases, it can be challenging to determine whether the death was caused by a deliberate act (for example, not taking or overdosing on life-saving drugs or an accident or a voluntary fall and so on $)^{21}$.

In particular, in many Western countries, regulations regarding the prescription of opioids (used to reduce somatic pain) are lax and could give older people fairly easy access to an effective suicide method $^{21}$. It is then known that the death of an older person usually incurs less investigative interest than the death of a young person or a death associated with a medical procedure ${ }^{22}$.

Furthermore, cases of 'silent suicide' such as those due to voluntarily stopping eating and drinking (VSED) are generally not registered as suicide cases, even if, in an obvious sense, VSED is a true suicide case, given that the person's intention is to die ${ }^{23}$. Food and water are essential for life; deciding to renounce these elements is done to hasten death. Therefore, VSED is a suicide attempt, not

${ }^{1}$ Australian Institute for Suicide Research and Prevention, Griffith University, Brisbane, Queensland, Australia. ${ }^{2}$ Slovenian Center for Suicide Research,

Primorska University, Koper, Slovenia.凶e-mail: d.deleo@griffith.edu.au 


\section{Box 1 | Warning signs of suicide risk in older adults}

\section{The individual}

- appears sad or depressed most of the time.

- feels anxious, agitated or unable to sleep or sleeps all the time.

- has frequent and dramatic mood swings.

- neglects personal hygiene and no longer pays attention to physical appearance.

- does not want to see friends or family and no longer has a social life.

- expresses disproportionate feelings of guilt or shame.

- loses interest in food.

- has appreciably increased consumption of cigarettes and alcohol.

- talks about death (for example, 'I've had enough' or 'it makes no sense to continue').

- puts business in order.

- labels own things.

- makes a will or changes the will.

- gives away objects of emotional importance.

- has put aside pills and other non-therapeutic drugs.

- unexpectedly has visited relatives and friends as if to say goodbye.

(Modified from ref. ${ }^{82}$ ).

only a desire to reduce food and liquids as a natural consequence of some terminal conditions ${ }^{24}$. As described by Pope ${ }^{25}$, VSED has long remained an option to end life in a hidden way; today the debate about VSED is more open, and doctors (especially oncologists) should be well prepared to manage requests of their terminally ill patients. Because VSED represents a possible response to terminal illness, this contributes greatly to its moral acceptability as a form of suicide ${ }^{25}$.

Other than VSED, patients with terminal illness may ask their doctors to accelerate their death in another way and be assisted to do this. Medical aid for dying is not yet an accepted practice in most countries of the world. Australia has proven to be one of the most active countries in debating these issues, with the Queensland Parliament recently approving the law on voluntary assisted dying (VAD), following a decision similar to that of the parliaments of Victoria, Western Australia, Tasmania and South Australia. To be eligible to access VAD in Queensland, a person must be an adult, have a progressive condition that is expected to cause death within 12 months and causing intolerable suffering, have decision-making capacity and be acting voluntarily and without coercion ${ }^{26}$.

The spread of euthanasia practices is even more limited. Spain has recently become the sixth country worldwide to acknowledge the right to euthanasia, after the Netherlands, Belgium, Luxembourg, Canada and New Zealand. Several US states allow assisted dying, while Switzerland permits assisted suicide for 'unselfish reasons ${ }^{27}$. Swiss law tolerates assisted suicide when patients effect the act themselves and helpers have no vested interest in their death. The law prohibits doctors, spouses, children or other such related parties from directly participating in one's death. In Switzerland, two main groups operate in this area: Exit and Dignitas. While Dignitas also assists people from abroad, Exit only supports citizens or permanent residents of Switzerland in taking their own life. In 2020, Exit helped 1,282 people, mostly affected by terminal illnesses, to die ${ }^{28}$. While the number of assisted suicides appears to be growing, to some extent this might reflect the aging population in Switzerland. Total figures of assisted suicide cases are not included in the official count of suicide cases for Switzerland ${ }^{28}$.

\section{Box 2 | Quick glossary of terms}

Ageism Discriminating against or stereotyping individuals on the basis of their age.

VSED Act performed by individuals physically and mentally able to eat and drink who consciously refuse to eat and drink with the intent of hastening their own death.

Assisted suicide Suicide effected with the help of another person, usually by providing lethal drugs.

VAD Term used mainly in Australia; it refers to assistance provided to an individual by a health practitioner to end their life.

Euthanasia Action performed by a doctor to end an individual's life by a painless means, with consent of the patient and/or their family.

Suicide Act to intentionally provoke one's own death.

Suicidal ideation Broad category of fantasies about, contemplation of, preoccupation with and wishes for suicide.

Suicidal behavior Broad category of suicidal threats, gestures, self-harming behavior and suicide attempts.

SDH Those non-medical factors able to influence health outcomes. They are the conditions in which people are born, grow, work, live and age ${ }^{4}$.

Human rights of older adults Older persons should be able to enjoy human rights and fundamental freedoms when residing in any shelter or care or treatment facility, including full respect for their dignity, beliefs, needs and privacy and for the right to make decisions about their care and the quality of their lives ${ }^{83}$.

\section{What impact has the pandemic had, if any?}

Studies that specifically clarify the impact of the COVID-19 pandemic on rates of death from suicide among older adults are not available yet; however, it is conceivable that the pandemic has a negative impact on suicide in old age ${ }^{29}$. The 2003 severe acute respiratory syndrome (SARS) outbreak in Hong Kong was associated with an increase in the number of suicides in old age, especially in women. Compared to previous years, the increase was $30 \%$ of the expected numbers ${ }^{30}$.

In Japan, after an initial decline in suicide rates during the first wave of the pandemic, a $16 \%$ increase was noted during the second wave (July to October 2020), with women experiencing the largest increase $^{31}$. Japan has appointed a minister of loneliness (Tetsushi Sakamoto) after seeing suicide rates in the country rise for the first time in 11 years. Factors such as social distancing, quarantine, personal protective equipment, loneliness and the inability to contact loved ones (even for the last goodbye) have the potential to aggravate anxiety, depression and post-traumatic stress symptoms, potential triggers of self-harm and suicide episodes ${ }^{32,33}$. The limited availability of institutions able to provide real-time suicide data (R. Benson et al., unpublished) thus far has provided a non-alarming picture in terms of suicide outcomes. Studies carried out in Australia ${ }^{34}$ and the $\mathrm{UK}^{35}$ have not shown any particular increase in the number of suicides among older adults. However, in particular for older adults living in nursing homes, the current global health crisis has had traumatizing effects in terms of psychological suffering as well as mortality due to the pandemic ${ }^{36}$. Apparently, this did not translate into an increase in suicide mortality, despite some subgroups of the 


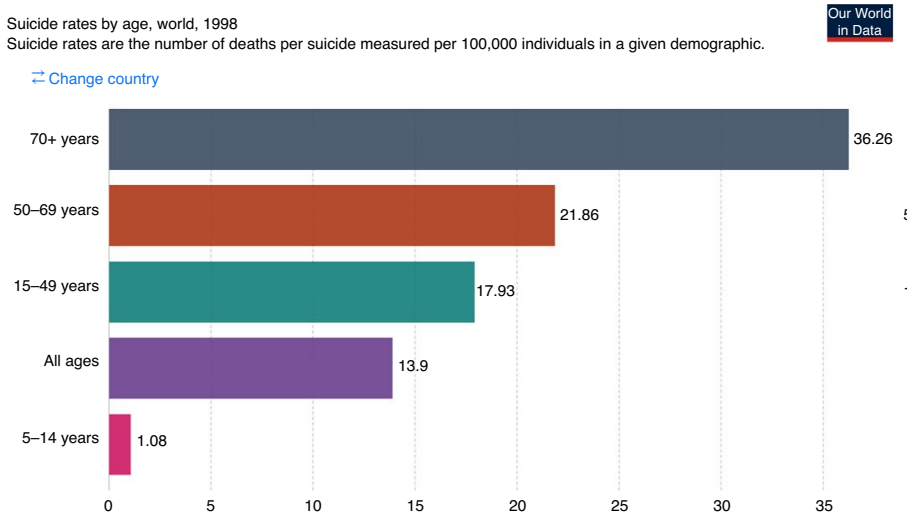

Source: IHME, Global Burden of Disease $\begin{array}{ccc}25 & 30 & 35 \\ \text { https://ourworldindata.org/suicide } & \bullet \text { CC BY }\end{array}$
Suicide rates by age, world, 2017

Suicide rates are the number of deaths per suicide measured per 100,000 individuals in a given demographic. $\longrightarrow$ Change country

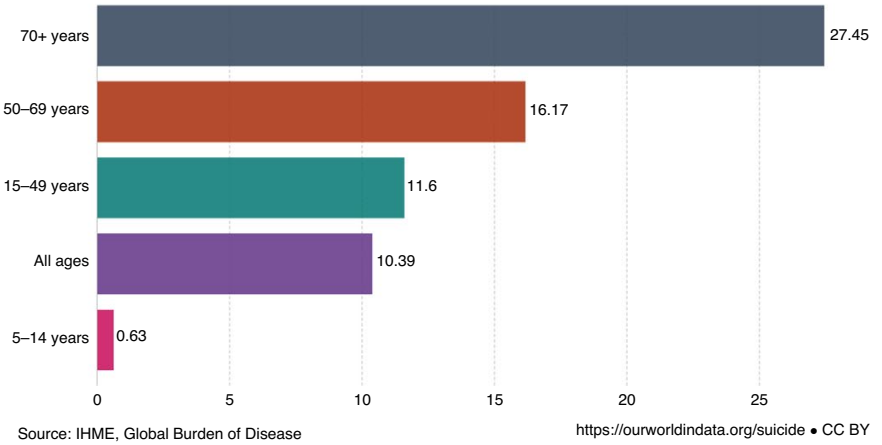

Fig. 1 | Global Burden of Disease Study: world rates of suicide, 1998 and 2017. IHME, Institute for Health Metrics and Evaluation.

population-for example, those who are jail inmates or are socially 'fragile' (such as bullied persons) — being more exposed to suicide risk factors ${ }^{37,38}$.

During the pandemic, many media representations of aging were particularly disturbing and inadequate. They made older adults feel a charge to society and to their families; they made them aware that they might be denied care or considered less deserving of $\mathrm{it}^{39,40}$. These factors can cause feelings of loss of value and meaning and compromise the feeling of independence ${ }^{41,42}$. Furthermore, people who ask for help might feel exposed, in particular, if the request is due to suicidal behavior, mental illness and substance abuse.

A further element of concern is the difficulty in accessing health care, especially in low- and middle-income countries ${ }^{43}$. For older people specifically, inadequate access to help is likely to have negative consequences ${ }^{44}$. This problem tends to worsen in emergency situations, such as in the current pandemic. The reduction of usual care for somatic and psychiatric diseases ${ }^{45}$, the lack of adequate staff, the limitation of provisions for people living in long-term care facilities ${ }^{46}$, the abolishment of outpatient visits, home services and public transport as well as long waiting times ${ }^{47,48}$ are all elements capable of increasing mental distress and thus can cause a rise in suicide risk ${ }^{49}$.

Actually, as shown in a survey by Carstensen et al. ${ }^{50}$ on a sample of 945 American individuals between the ages of 18 and 76 years, during the spreading of the pandemic, older adults showed relatively greater emotional well-being than younger adults and this persisted even in the face of prolonged stress. Similar results were obtained by another survey performed during March and April 2020 on a sample of 776 individuals aged 18-91 years from Canada and the USA ${ }^{51}$. Furthermore, another study suggested that older age leads to a greater focus on positive aspects of the initial phases of the pandemic ${ }^{52}$

These findings appear to be in line with Carstensen et al.s theory of socio-emotional selectivity ${ }^{53}$. According to this theory, with aging, people realize that the time at their disposal is limited and become more inclined to focus on the present than the future. They place more value on meaningful social ties and less on embarking on new adventures. This motivational change leads to greater investment in the quality of social relations and a general appreciation of life ${ }^{53}$. Relying on emotion-centered strategies can contribute to a greater sense of older adults' control over their emotions ${ }^{54}$. A limited-time perspective may also explain the increased focus on emotional coping strategies with age.

Stress factors are present throughout the course of life. For people who perceive time as more limited, the future appears less important, while the emotional meaning of present situations increases in relevance. An emotions-focused approach to managing stress can therefore be used more frequently and result in better psychological outcomes $^{53}$. Even if the intensity of experienced negative emotions is similar across all ages of life, older people are faster in returning to positive states than younger people $\mathrm{e}^{55}$. Greater emotional control with age may help to explain why older adults report high levels of life satisfaction, nonwithstanding the losses experienced later in life ${ }^{56}$. Furthermore, older people have lower rates of mental health disorders compared to younger people $\mathrm{e}^{57}$.

\section{Unique challenges}

Most often, suicide in old age is presumed to be a rational act. Shortened lifespans, lack of positive outlooks, frailty, dependence on others, loss of a partner and loneliness are reasons that can provide a possible explanation for many cases of suicide. The aggregation of several risk factors, such as bereavement over the death of a partner, experiencing dependence and experiencing illness, can reinforce the paradigm of the rationality of suicidal behavior. Along the same lines, suicide might be considered a rightful choice in light of experiences such as loss of personal reputation and dignity, or if there is a dramatic change in status and social role. Situations such as those described above are often conceived as inevitably characterized by severe forms of depression, but this view is also heavily imbued with prejudices about the value of life in old age.

'Ageism', as defined by the World Health Organization, is a set of stereotypes, prejudices and discrimination that are based on age ${ }^{4}$. Often the public portrayal of old age is characterized by psychophysical decline, helplessness and fragility. These detrimental representations of old age might impact care options for older people. Furthermore, internalization of ageist narratives can result in a negative view of life and in the perpetuation of the common view of older people belonging to a disadvantaged subgroup of the population $^{58}$. These psychosocial processes are confounded by ageism as portrayed in the press and social media ${ }^{59,60}$.

The roots of ageism have a long tradition. More than 2,000 years ago, Terentius, in his Phormio, wrote that 'senectus ipsa morbus est' (old age is in itself a disease) ${ }^{61}$. The accumulation of life events, losses and physical illnesses has fueled the view that older people rationally choose, for 'right reasons', to prematurely end their lives. Over the years, this interpretation has been replaced by the conception of older people as being almost always overwhelmed by their emotions, depressed to the point of seeing suicide as the only opportunity to stop their pains. Therefore, the medical world has paid the utmost attention to the therapy of affective disorders. However, depression is not the obvious answer to any type of stress, such as a sudden decrease in physical health or the onset of financial difficulties. The term 'depression', therefore, should be reserved only 
to describe a pathological state and not the supposedly foreseeable response to certain stress factors.

While there are different forms of depression that have distinct etiologies, all are characterized by an increased risk of suicide ${ }^{62}$. The central concept in depression is 'loss', and, as such, depression seems to align particularly well with the perceived 'fragility' of old age, somatic disorders and cognitive deficits, experiences of loneliness and loss of interest ${ }^{63}$. Not infrequently, these emotional experiences lead the person to 'tunnel vision', with suicide appearing as the only viable alternative and, perhaps, the only form of control over one's life (the ultimate power) still achievable, especially in those people (more often men) who have been 'people of action' throughout their life ${ }^{64}$.

However, while depression is clearly a major risk factor for suicidal behavior (including in old age), arguably its role has been generalized more than necessary and it has been turned into the scapegoat for any suicidal behavior. In fact, sadness, disappointment, bitterness, loneliness and lack of hope for the future are frequent travel companions throughout the life of any individual and not necessarily clinical symptoms of an illness. As such, their presence should not always be indicative of pathology, as they are quite common feelings, sooner or later experienced by most individuals. But, then, when does a common mood such as sadness turn into depression (that is, a mental disorder)? It has been hypothesized that this occurs when the psychological reaction to an unfavorable life event does not appear to be related to it or is disproportionate or when there is a particular qualitative dimension in the reaction; that is, when it constitutes a 'gestalt' (an entity that is more than the sum of the elements that compose it) or, for pragmatic reasons, when it is assumed that there is a continuum of severity that ranges from sadness to clinical depression ${ }^{65}$. Apparently, many psychiatrists tend to favor the latter interpretation in qualifying a condition as 'depressive' in psychiatric terms ${ }^{65}$. In old age, people tend to be more often viewed with this way of thinking, which reflects anti-aging attitudes that are still widespread, even among doctors themselves ${ }^{64}$.

Mental health is affected by a number of determinants over the course of life; these determinants can accumulate in old age. Social determinants of health $(\mathrm{SDH})$ are the conditions in which people are born, grow up, work and age and are affected by socio-environmental circumstances. These SDH are related to depression as well as other mental disorders and contribute to their onset or course. $\mathrm{SDH}$ may alternatively have a role as risk factors (for example, poverty, loss, relocation, migration, stigma and discrimination) or as protective factors (for example, good quality of family interactions, good social protection and intense spiritual life). By leveraging the $\mathrm{SDH}$, one can improve mental health of older people ${ }^{66}$. This type of strategy, in itself non-medical stricto sensu, is however central in the fight against ageism and essential to the prevention of suicide.

\section{Clinical treatment and suicide prevention}

Ageism deteriorates care options for older adults: from normalizing depression in late life to fostering reluctance to intervene clinically, given the fragility of health of older patients and the fear of harmful drug-drug interactions ${ }^{67,68}$. These attitudes and misunderstandings can lead to underappreciation of the severity of a depressive disorder and simultaneously minimizing the complexity of an older person's problems, flattening prospects for appropriate care ${ }^{66}$.

From the perspective of suicide prevention, there may be contradictory aspects in qualifying a condition as depressive. In clinical practice, approaching patient care with attention and prudence is better than to presume that life stressors, as well as all reactions connected to them, are inevitable. However, there are cultural scripts and common attitudes that can interfere with the best possible clinical management. These attitudes are particularly dangerous especially in the clinical management of older patients also because biopsychosocial stress factors (for example, chronic diseases, bereavement, social invisibility and so on) easily aggregate, multiplying their power ${ }^{19}$.

On the contrary, assuming that attitude in which every difficulty reported by the patient becomes attributable to a depressive illness implies an oversimplification of the problems and can lead to a hasty prescribing approach, often limited to the sole indication of an antidepressant drug. In this way, appreciation of the multifactorial nature and complexity of a given patient's situation becomes too modest and the chances of countering a dangerous suicidal progression may be reduced. If there are no known miracle remedies for depression, there certainly are no 'one-size-fits-all' solutions for suicidal behavior. Furthermore, older people experiencing mental disorders are less likely to seek out psychiatrists and specialist services but rather prefer to approach their general practitioner to discuss health problems ${ }^{69}$.

In any case, prescription drugs alone may rarely be enough to make a difference for a person contemplating suicide. Pharmacological treatments should very often be supplemented (and sometimes replaced) by psychological treatments. Equally often, if not always, appropriate psychosocial interventions should be arranged. Unfortunately, these remedies do represent a traditionally problematic area for doctors: they are usually not part of their professional training and often tend to be considered of secondary importance, a kind of 'soft therapy'. For this reason, these remedies are generally delegated to psychologists and social workers. On the contrary, in my opinion, the 'social prescriptions' of the UK national health system may represent an important complement to traditional care. Even if further research is needed to understand how social prescriptions can be applied efficiently to a variety of conditions ${ }^{70,71}$, social prescriptions appear to be promising health care interventions, useful in integrating the traditional biomedical model of care ${ }^{72,73}$.

As far as training in the area of suicidal behavior prevention is concerned, this remains a need of primary importance: certainly much more could be achieved in this area with adequate preparation $^{74,75}$. Preventing suicide should be a shared commitment, and multidisciplinary teamwork appears today to be the most logical approach. The task of respecting the dignity of old people and fighting ageist views of old age remains problematic; equal determination should be involved in the fight against the stigma associated with mental disorders and suicidal behaviors ${ }^{76}$.

\section{Conclusions}

A fatalistic attitude toward the problem of suicide in late life conveys a materialistic and dismissive message to younger members of society, who instead need examples of courage and determination to live a meaningful life and nurture an authentic sense of belonging to the community.

Combating stigma and discrimination against older people, as well as promoting basic SDH, would help to prevent suicide ${ }^{76}$. However, these issues are still very under-represented in the global agenda of health care. While having an effective impact on the numerous forms of discrimination would require legal interventions by governments, fighting stigma would primarily involve education aimed at changing beliefs and attitudes ${ }^{77}$. Actions against stigma and discrimination must be sensitive to the local culture; their main objective must be the promotion of human rights, with particular regard to protection against abandonment, abuse and violence (especially deleterious aspects in old age $)^{76}$. A human rights-based approach for older individuals essentially aims at their personal empowerment. Once they become more powerful, older people would also become more capable of defending their interests in terms of quality of life and protection against risk factors for suicide ${ }^{78}$.

Suicide prevention in old age should greatly expand its portfolio of interventions and direct more attention to the numerous socio-environmental conditions that can be particularly worrisome 
in old age, such as decreased physical health, social isolation and loneliness and financial insecurity. All of this could be crucial to counter suicidal ideation and behavior. The goal should not only be preventing suicide but also improving the quality of life of older adults to reduce factors that contribute to depression and suicidal ideation. While not all problems should be interpreted as symptoms of depression, both identification and early treatment of affective disorders and improvement of social support remain key interventions to reduce the risk of suicide in old age ${ }^{79}$.

It is crucial that governments continue to improve retirement programs, facilitate access to health care (in particular, mental health services), and create supportive social systems. The problem of loneliness with its many facets must be tackled and certainly with enhanced determination ${ }^{80}$. It remains a categorical imperative to test the real validity of any actions taken, with particular attention to identifying individual components of each prevention program and their respective impact and to ensure that they are tailored to different cultural contexts.

The fight against stigma and the ageist way of thinking, which is pervasive in society, including among health professionals, must be pursued with great vigor ${ }^{81}$. Additionally, successful aging requires promoting a culture of resilience and adaptation to the different stages of life as well as to the changes that come with advancing age. Promoting human rights of older people is an essential step in the path leading to this success.

Received: 10 August 2021; Accepted: 6 December 2021; Published online: 20 January 2022

\section{References}

1. Naghavi, M. Global, regional, and national burden of suicide mortality 1990 to 2016: systematic analysis for the Global Burden of Disease Study 2016. BMJ 364, 194 (2019).

2. Wand, A., Draper, B., Brodaty, H. \& Peisah, C. Self-harm in the very old one year later: has anything changed? Int. Psychogeriatr. 31, 1559-1568 (2019).

3. Fazel, S. \& Runeson, B. Suicide. N. Engl. J. Med. 382, 266-274 (2020).

4. World Health Organization (WHO). Global Report on Ageism (WHO, 2021).

5. De Leo, D. \& Heller, T. Social modelling in the transmission of suicidality. Crisis 29, 11-19 (2008).

6. Shah, A., Bhat, R., Zarate-Escudero, S., De Leo, D. \& Erlangsen, A. Suicide rates in five-year age-bands after the age of 60 years: the international landscape. Aging Ment. Health 20, 131-138 (2016).

7. World Health Organization (WHO). Global Health Observatory Data Repository-Suicide Rate Estimates, Crude, 10-Year Age Groups. Estimates by Country https://apps.who.int/gho/data/node.main.MHSUICIDE10YEARAGE GROUPS?lang=en (WHO, 2018).

8. Shah, A., Zarate-Escudero, S., Bhat, R., De Leo, D. \& Erlangsen, A. Suicide in centenarians: the international landscape. Int. Psychogeriatr. 26, 1703-1708 (2014).

9. Organisation for Economic Co-operation and Development. Going for Growth 2021: Shaping a Vibrant Recovery (2021).

10. Wand, A. et al. Is suicide the end point of ageism and human rights violations? Am. J. Geriatr. Psychiatry 29, 1047-1052 (2021).

11. Kent, M. Old age. In The Oxford Dictionary of Sports Science \& Medicine 3rd edn (Oxford, 2007).

12. Ahadi, S. et al. Personal aging markers and ageotypes revealed by deep longitudinal profiling. Nat. Med. 26, 83-90 (2020).

13. World Health Organization (WHO). Indicators for the Minimum Data Set Project on Ageing: a Critical Review in Sub-Saharan Africa https://www.who. int/healthinfo/survey/ageing_mds_report_en_daressalaam.pdf (WHO, 2001).

14. De Leo, D., Draper, B. \& Krysinska, K. Suicidal elderly people in clinical and community settings: risk factors, treatment and suicide prevention. In Oxford Textbook of Suicidology and Suicide Prevention: a Global Perspective (eds Wasserman, D. and Wasserman, C.) Part 13, 703-719 (Oxford University Press, 2009).

15. Steffens, D. C. et al. Prevalence of depression and its treatment in an elderly population. The Cache County study. Arch. Gen. Psychiatry 57, 601-607 (2000)

16. World Health Organization (WHO). Depression and Other Common Mental Disorders (WHO, 2017).

17. De Leo, D., Draper, B., Snowdon, J. \& Kolves, K. Suicides in older adults: a case-control psychological autopsy study in Australia. J. Psychiatr. Res. 47, 980-988 (2013).
18. Fiske, A., Loebach Wetherell, J. \& Gatz, M. Depression in older adults. Annu. Rev. Clin. Psychol. 5, 363-389 (2009).

19. Koo, Y. W., Kõlves, K. \& De Leo, D. Suicide in older adults: differences between the young-old, middle-old, and oldest-old. Int. Psychogeriatr. 29, 1297-1306 (2017).

20. Williams, R. F., Doessel, D. P., Sveticic, J. \& De Leo, D. Accuracy of official suicide mortality data in Queensland. Aust. NZ J. Psychiatry 44, 815-822 (2010).

21. De Leo, D. \& Arnautovska, U. Prevention and treatment of suicidality in older adults. In International Handbook of Suicide Prevention. Research, Policy and Practice (eds O'Connor, R. \& Pirkis, J.) 323-345 (Wiley Blackwell, 2016).

22. Walter, S. J., Bugeja, L., Spittal, M. J. \& Studdert, D. M. Factors predicting coroners' decisions to hold discretionary inquests. CMAJ 185, 522-528 (2012).

23. Wax, J. W. et al. Voluntary stopping eating and drinking. J. Am. Geriatr. Soc. 66, 441-445 (2018).

24. Quill, T. E. et al. Voluntarily stopping eating and drinking among patients with serious advanced illness-clinical, ethical, and legal aspects. JAMA Intern. Med. 178, 123-127 (2018).

25. Pope, T. M. Voluntarily stopping eating and drinking (VSED) to hasten death: may clinicians legally support patients to VSED? BMC Med. 15, 187 (2017).

26. McKenna, K., Gramenz, E. \& Kleyn, B. Applause in Queensland Parliament Gallery as historic bill passed, legalising voluntary assisted dying. ABC News (17 September 2021).

27. Rada, A. G. Spain will become the sixth country worldwide to allow euthanasia and assisted suicide. BMJ 372, n147 (2021).

28. SWISS-Info. Assisted suicide option remains in demand in Switzerland. Swissinfo.ch/mga (22 February 2021).

29. Wand, A. P. F., Zhong, B. L., Chiu, H. F. K., Draper, B. \& De Leo, D. COVID-19: the implications for suicide in older adults. Int. Psychogeriatr. 32, 1225-1230 (2020).

30. Chan, S. M., Chiu, F. K., Lam, C. W., Leung, P. Y. \& Conwell, Y. Elderly suicide and the 2003 SARS epidemic in Hong Kong. Int. J. Geriatr. Psychiatry 21, 113-118 (2006).

31. Tanaka, T. \& Okamoto, S. Increase in suicide following an initial decline during the COVID-19 pandemic in Japan. Nat. Hum. Behav. 5, 229-238 (2021).

32. De Leo, D. \& Trabucchi, M. COVID-19 and the fears of Italian senior citizens. Int. J. Environ. Res. Public Health 7, 3572 (2020).

33. Santini, Z. I. et al. Social disconnectedness, perceived isolation, and symptoms of depression and anxiety among older Americans (NSHAP): a longitudinal mediation analysis. Lancet Public Health 5, e62-e70 (2020).

34. Leske, S., Kolves, K., Crompton, D., Arensma, E. \& De Leo, D. Real-time suicide mortality data from police reports in Queensland, Australia, during the COVID-19 pandemic: an interrupted time-series analysis. Lancet Psychiatry 8, 58-63 (2021).

35. Appleby, L. What has been the effect of COVID-19 on suicide rates? BMJ 372, n834 (2021).

36. Trabucchi, M. \& De Leo, D. Nursing homes or besieged castles: COVID-19 in northern Italy. Lancet Psychiatry 7, 387-388 (2020).

37. Brunstein Klomek, A., Sourander, A. \& Gould, M. The association of suicide and bullying in childhood to young adulthood: a review of cross-sectional and longitudinal research findings. Can. J. Psychiatry 55, 282-288 (2010).

38. Fazel, S., Grann, M., Kling, B. \& Hawton, K. Prison suicide in 12 countries: an ecological study of 861 suicides during 2003-2007. Soc. Psychiatry Psychiatr. Epidemiol. 46, 191-195 (2011).

39. De Leo, D. \& Trabucchi, M. The fight against COVID-19: a report from the Italian trenches. Int. Psychogeriatr. 32, 1161-1164 (2020).

40. Wenger, N. S. \& Schapiro, M. F. Op-ed: as hospitals become overwhelmed with coronavirus, how do we decide who gets treatment? Los Angeles Times (26 March 2020).

41. Crocker, L., Clare, L. \& Evans, K. Giving up or finding a solution? The experience of attempted suicide in later life. Aging Ment. Health 10, 638-647 (2006)

42. Wand, A. P. F., Peisah, C., Draper, B. \& Brodaty, H. Understanding self-harm in older people: a systematic review of qualitative studies. Aging Ment. Health 22, 289-298 (2018).

43. Cho, J. et al. Medical care utilization during 1 year prior to death in suicides motivated by physical illnesses. J. Prev. Med. Public Health 46, 147-154 (2013).

44. Heinsch, M. et al. Understanding ambivalence in help-seeking for suicidal people with comorbid depression and alcohol misuse. PLoS ONE 15, e0231647 (2020)

45. Yao, H., Chen, J. H. \& Xu, Y. F. Patients with mental health disorders in the COVID-19 epidemic. Lancet Psychiatry 7, e21 (2020).

46. Thomas, M. A. The Impact of COVID-19 on People with Severe and Complex Mental Health Problems. Concerted Action Needed Urgently (UCL Institute of Mental Health, 2020).

47. Reger, M. A., Stanley, I. H. \& Joiner, T. E. Suicide mortality and coronavirus disease-2019. A perfect storm? JAMA Psychiatry 77, 1093-1094 (2020).

48. Uibu, K. Carers for family members withdraw from support services to limit contact during coronavirus pandemic. ABC News (6 April 2020). 
49. Yang, Y. et al. Mental health services for older adults in China during the COVID-19 outbreak. Lancet Psychiatry 7, e19 (2020).

50. Carstensen, L. L., Shavit, Y. S. \& Barnes, J. T. Age advantages in emotional experience persist even under threat from the COVID-19 pandemic. Psychol. Sci. 31, 1374-1385 (2020).

51. Klaiber, P., Wen, L. H., DeLongis, A. \& Sin, N. L. The ups and downs of daily life during COVID-19: age differences in affect, stress, and positive events. J. Gerontol. B Psychol. Sci. Soc. Sci. 76, e30-e37 (2021).

52. Ford, J. H., Garcia, S. M., Cunningham, Y. J. \& Kensinger, E. A. Older adults remember more positive aspects of the COVID-19 pandemic. Psychol. Aging 36, 694-699 (2021).

53. Carstensen, L. L., Helene, H., Fung, H. H. \& Charles, S. T. Socioemotional selectivity theory and the regulation of emotion in the second half of life. Motiv. Emot. 27, 103-123 (2003).

54. Gross, J. J. et al. Emotion and aging: experience, expression, and control. Psychol. Aging 12, 590-599 (1997).

55. Carstensen, L. L., Pasupathi, M., Mayr, U. \& Nesselroade, J. R. Emotional experience in everyday life across the adult life span. J. Pers. Soc. Psychol. 79, 644-655 (2000).

56. Diener, E. \& Suh, E. Measuring quality of life: economic, social, and subjective indicators. Soc. Indic. Res. 40, 189-216 (1997).

57. de Graaf, R., ten Have, M., van Gool, C. \& van Dorsselaer, S. Prevalence of mental disorders and trends from 1996 to 2009. Results from the Netherlands Mental Health Survey and Incidence Study-2. Soc. Psychiatry Psychiatr. Epidemiol. 47, 203-213 (2012).

58. Swift, A. J., Abrams, D., Lamont, R. \& Drury, L. The risks of ageism model: how ageism and negative attitudes toward age can be a barrier to active aging. Soc. Issues Policy Rev. 11, 195-231 (2017).

59. Levy, B. R., Chung, P. H., Bedford, T. \& Navrazhina, K. Facebook as a site for negative age stereotypes. Gerontologist 54, 172-176 (2013).

60. Zebrowitz, L. A. \& Montepare, J. M. “Too young, too old”: stigmatizing adolescents and elders. In The Social Psychology of Stigma (eds Heatherton, T. F., Kleck, R. E., Hebl, M. R. \& Hull, J. G.) 334-373 (Guilford Press, 2000).

61. Terence (161B.CM./2021). Phormio. Wikipedia, https://en.wikipedia.org/wiki/ Phormio_(play) (2021).

62. Blazer, D. G. Depression in late life: review and commentary. J. Gerontol. A Biol. Sci. Med. Sci. 58, 249-265 (2003).

63. Freud, S. Mourning and melancholia. In The Standard Edition of the Complete Psychological Works of Sigmund Freud, Volume XIV (1914-1916): On the History of the Psycho-Analytic Movement, Papers on Metapsychology and Other Works 237-258 (Hogart Press, 1917).

64. De Leo, D. Suicidal behavior in late life: reasons and reactions to it. Int. Psychogeriatr. 31, 1531-1533 (2019).

65. Maj, M. When does depression become a mental disorder? $\mathrm{Br}$. J. Psychiatry 199, 85-86 (2011)

66. De Mendonça Lima, C. A. Social determinants of health and promotion of mental health in old age. In Social Determinants and Mental Health (ed. Bährer-Kohler, S.) 203-213 (Nova Science Publishers, 2011).

67. Rabheru, K. Special issues in the management of depression in older patients. Can. J. Psychiatry 49, 41-50 (2004).

68. De Leo, D. Ageism and suicide prevention. Lancet Psychiatry 5, 192-193 (2018)

69. Skultety, K. M. \& Rodriguez, R. L. Treating geriatric depression in primary care. Curr. Psychiatry Rep. 10, 44-50 (2008).
70. Husk, K., Julian Elston, J., Felix Gradinger, F., Lynne Callaghan, L. \& Sheena Asthana, S. Social prescribing: where is the evidence? Br. J. Gen. Pract. 69, 6-7 (2019).

71. Costa, A. et al. Effectiveness of social prescribing programs in the primary health-care context: a systematic literature review. Sustainability 13, 2731 (2021)

72. The Lancet. UK life science research: time to burst the biomedical bubble. Lancet 392, 187 (2018).

73. Braslow, J. T., Brekke, J. S. \& Levenson, J. Psychiatry's myopia-reclaiming the social, cultural, and psychological in the psychiatric gaze. JAMA Psychiatry 78, 349-350 (2021).

74. Hawgood, J., Krysinska, K., Ide, N. \& De Leo, D. Is suicide prevention properly taught in medical schools? Med. Teach. 30, 287-295 (2008).

75. Hawgood, J. et al. Suicidology post-graduate curriculum: priority topics and delivery mechanisms for the suicide prevention workforce in Australia. Int. J. Environ. Res. Public Health 18, 9926 (2021).

76. De Mendonça Lima, C. A., De Leo, D., Ivbijaro, G. \& Svab, I. Suicide prevention in older adults. Asia Pac. Psychiatry 13, e12473 (2021).

77. Graham, N. et al. Reducing stigma and discrimination against older people with mental disorder: a technical consensus statement. Int. J. Geriatr. Psychiatry 18, 670-678 (2003).

78. UNDESA \& United Nations Human Rights Office of High Commissioner. Open-Ended Working Group on Ageing for the Purpose of Strengthening the Protection of the Human Rights of Older Persons https://social.un.org/ageingworking-group (2010).

79. Lapierre, S. et al. Systematic review of elderly suicide prevention programs. Crisis 32, 88-98 (2011).

80. Berg-Weger, M. \& Morley, J. E. Loneliness in old age: an unaddressed health problem. J. Nutr. Health Aging 24, 243-245 (2020).

81. De Mendonça Lima, C. A., De Leo, D., Ivbijaro, G. \& Svab, I. Loneliness and abuse as risk factors for suicide in older adults: new developments and the contribution of the WPA Section on Old Age Psychiatry. World Psychiatry 20, 455-456 (2021)

82. De Leo, D. I comportamenti sucidari degli anziani (suicidal behaviour of older adults). Supplemento di Psicogeriatria N.1, 1-74 (2017).

83. United Nations Human Rights, Office of the High Commissioner. United Nations Principles for Older Persons (1991).

\section{Author contributions}

D.D.L. is the only contributor to the piece.

\section{Competing interests}

The author declares no competing interests.

\section{Additional information}

Correspondence should be addressed to Diego De Leo.

Reprints and permissions information is available at www.nature.com/reprints.

Publisher's note Springer Nature remains neutral with regard to jurisdictional claims in published maps and institutional affiliations.

(c) Springer Nature America, Inc. 2022 